\title{
APPLICATION OF DEXAMETHASONE AS AN ADJUVANT TO THE LOCAL ANESTHETIC IN THE PERFORMANCE OF A US-GUIDED FEMORAL BLOCK FOR POSTOPERATIVE ANALGESIA ON PATIENTS AFTER TOTAL KNEE JOINT REPLACEMENT
}

\author{
Petya Ivanova, Nikolay Mladenov, Atanas Zanev, Viliyan Platikanov, Katerina Ilieva \\ Department of Anesthesiology and Intensive Care, Faculty of Medicine, \\ Medical University of Varna
}

\section{ABSTRACT}

INTRODUCTION: The article discusses the use of dexamethasone as an adjuvant to local anesthetic solution for ultrasound (US)-guided femoral nerve block in patients after total knee joint replacement. A literature review on the clinical use of other adjuvants is also presented.

DESIGN: This was a clinical prospective randomized study.

AIM: The aim of this article is to investigate the effect of dexamethasone adjuvant on the local anesthetic solution when performing a US-guided femoral block in patients after total knee joint replacement.

METHODS: The study included 53 patients, randomized into two groups: Group 1: single shot femoral nerve block (FNB) + constant infusion through a perineural catheter $15 \mathrm{~mL}$ bolus (ropivacaine $0.5 \% /$ levobupivacaine $0.375 \%$ ) with a subsequent infusion of 5-9 $\mathrm{mL}$ per hour, including 20 patients; Group 2: single shot FNB $20 \mathrm{~mL}$ bolus (ropivacaine 0.5\%/levobupivacaine 0.375\%) \pm dexamethasone $4 \mathrm{mg}$, including 33 patients. In Group 2, 2 subgroups were formed: patients with single shot FNB with chirocain - 10 patients; patients with single shot FNB with ropivacaine - 23 patients. Of these, 15 patients were fasted with single shot FNB with ropivacaine + dexamethasone $4 \mathrm{mg}$, and 8 patients with pure ropivacaine.

Evaluation of effective control of pain relief symptoms was done on $2^{\text {td }}, 4^{\text {th }}, 6^{\text {th }}, 12^{\text {th }}, 18^{\text {th }}, 24^{\text {th }}$, and $36^{\text {th }}$ hours postoperatively according to the Visual Analogue Scale (VAS).

RESULTS: No statistically significant difference in VAS scores was observed between the two groups in the $2^{\text {nd }}, 6^{\text {th }}, 12^{\text {th }}, 18^{\text {th }}$ and $36^{\text {th }}$ hours. Such was found only in the $24^{\text {th }}$ hour. We did not detect statistically significant benefits of this adjuvant. We do not have clinically registered adverse drug reactions (ADRs). We have not established a correlation between these occurrences and the use of dexamethasone.

CONCLUSION: Although our results correspond to those of authors who refute the benefits of dexamethasone as an adjuvant to the peripheral nerve block (PNB), we believe, based on clinical observation data,

Address for correspondence:
Petya Ivanova
Faculty of Medicine
Medical University of Varna
55 Marin Drinov St
9002 Varna
e-mail: pivanova82@gmail.com

Received: September 2, 2018

Accepted: September 28, 2018 that it actually attenuated reversible hyperalgesia (patients did not report abruptly, acute, sudden onset of pain), therefore prolongation of the analgesic effect was observed until the $18^{\text {th }}, 20^{\text {th }}$ postoperative hour.

Keywords: dexamethasone, adjuvant, US-guided femoral block, postoperative pain relief, knee joint, total knee joint replacement 
Petya Ivanova, Nikolay Mladenov, Atanas Zanev et al.

\section{INTRODUCTION}

"The art of life is the art of avoiding pain"

Thomas Jefferson

Optimal control of perioperative pain continues to be a major challenge for physicians, anesthetists, intensive care specialists and surgeons. It allows the reduction of patient suffering and maximum satisfaction, early mobilization, shortened hospital stay, reduced registered complications, morbidity and mortality.

Major surgery is associated with severe perioperative stress on the body, reflecting both the physical condition as well as the psychological aspect of the individual and the quality of life of the patient.

Effective pain control in the perioperative and early postoperative period has a lower incidence of complications such as postoperative respiratory failure, deep vein thrombosis and pulmonary thromboembolism, lower cardiac risk, nosocomial infections, and postoperative delirium. Good pain control results in reduced hospital stays leading to the corresponding economic benefits and, last but not least, a better quality of life.

Ultrasound (US)-guided nerve blocks are a modern, safe, reliable method for perioperative and postoperative analgesia that allows the reduction of the use of more invasive methods - epidural analgesia, drastic reduction of doses of the applied opiates with all the resulting negative effects - nausea, vomiting, itching, constipation, attenuated immunological response, respiratory depression, sleepiness, etc.

Peripheral nerve block of $n$. femoralis under US control is a modern method allowing good perioperative pain control, early physiotherapy and mobilization, a lower incidence of postoperative complications observed in patients after prosthetic knee joint replacement. All of the above-mentioned benefits make it a preferential method for postoperative analgesia in the early postoperative period. It provides a low-risk blockade with no absolute contraindications. It is also applied in patients with coagulation disorders.

US navigation allows a modern, fast, non-traumatic and reliable method, a low frequency of re- corded complications in the implementation of peripheral nerve blocks.

When performing a peripheral nerve block, single shot or continuous infusion through a perineural catheter in modern anesthesia is recommended, two local anesthetics are recommended to be instilled levobupivacaine and ropivacaine. Their widespread popularity in contemporary regionalism is due to their safe profile in continuous infusion, lower cardiotoxicity and hemodynamic stability with lidocaine and bupivacaine, lack of neurotoxicity and demyelinating processes $(1,2)$ and, of course, their prolonged effect.

Numerous reports and studies to compare analgesic potency, duration, concomitant motor block to determine optimal local anesthetic, concentration, bolus volume, and speed and infusion concentration are present in the literature.

With regard to the addition of adjuvants to the local anesthetic, the use of vasoconstrictors is observed due to the risk of ischemic damage to the peripheral nerves caused by vasoconstriction of vasa nervorum.

The results for clonidine and dexmedetomidine are controversial, both in terms of the potential and prolonging effects, the occurrence of frequent undesirable hypotensive (3), and in case of doubt about the possible toxic effect of clonidine in peripheral nerves experimentally in animals.

More good results in the literature refer to dexmedetomidine (4). Clinical trials establish a real prolongation of peripheral nerve blocks (PNBs) with the addition of $100 \mathrm{mcg}$ of dexmedetomidine to a local anesthetic but there is frequent bradycardia requiring medication (5).

Absolute apogee in the literature was observed with the discovery of beneficial and potentiating effects of dexamethasone, administered both as an adjuvant to the local anesthetic in single shot PNBs and in direct intravenous application $(6,7,8)$.

Applied as an adjuvant, a significantly prolonged analgesic effect over 200 minutes and better results in the evaluation of postoperative pain on validated scales (VAS) $(9,10,11,12)$ is registered. In the last 2-3 years, the addition of dexamethasone adjuvant to a solution of a long-acting local anesthetic in performing PNBs is a tendency to avoid peri- 
Application of Dexamethasone as an Adjuvant to the Local Anesthetic in the Performance of a US-Guided Femoral Block ..

neural catheters as a more invasive method related to the risk of infection, nerve damage, frequent dislocation and migration into other anatomical spaces. Other drawbacks of catheter techniques are the higher cost, the requirement of a particular logistics organization, and more highly skilled staff, respectively.

Ethiopathogenetically, the effect of dexamethasone is most likely due to induced vasoconstriction and prolongation of local anesthetic activity and, on the other hand, to reduced nociceptive sensitivity of C-fibers through direct effect on glucocorticoid receptors and inhibition of potassium channels, and possible systemic anti-inflammatory effect $(13,14)$.

Dexamethasone primarily affects dynamic pain, and its use does not increase the risk of wound infection (15).
In 2015, Ke An and co-authors (16) cite other possible beneficial effects of dexamethasone added as an adjuvant. They reported transient neurotoxic activity and reduced reversible hyperalgesia following depletion of the block effect. Others, like Fredrickson Fanzca MJ and co-authors, consider that all these claims are subject to reassessment and the data on the described effects are not convincing enough $(17,18)$.

Regarding the dose of dexamethasone as an adjuvant to a local anesthetic solution, the majority of the authors consider that the higher dose does not lead to a greater prolongation of the blockade or better analgesia, but only increases the risk of systemic effects of corticosteroids. Doses of $4 \mathrm{mg}$ and $8 \mathrm{mg}$ dexamethasone were compared, with no significant difference in the quality of the block (9).

Table 1. Studies that examine the effect of dexamethasone as an adjunct to regional techniques dexamethasone with one-way results (19)

\begin{tabular}{|c|c|c|c|c|c|c|}
\hline Author & Primary Outcome & $\begin{array}{l}\text { Analgesia } \\
\text { Duration }\end{array}$ & $\begin{array}{c}\text { Block Analgesia } \\
\text { Quality }\end{array}$ & $\begin{array}{l}\text { Time to Addition- } \\
\text { al Analgesia }\end{array}$ & $\begin{array}{l}\text { Secondary } \\
\text { Outcomes }\end{array}$ & $\begin{array}{l}\text { Complications } \\
\text { Associated with } \\
\text { Dexamethasone }\end{array}$ \\
\hline Fredrickson & $\begin{array}{l}\text { Analgesic quality } \\
\text { and duration }\end{array}$ & $\begin{array}{l}\text { Increased analge- } \\
\text { sia at } 24 \mathrm{~h} \text { vs. no } \\
\text { change at } 48 \mathrm{~h}\end{array}$ & No difference & - & - & Nil noted \\
\hline Rahagdale & Analgesic duration & $\begin{array}{c}\text { Prolonged } 13 \\
\text { (perineural) vs. } \\
\text { 8(iv) vs. 6h control }\end{array}$ & - & & $\begin{array}{l}\text { No difference } \\
\text { postoperative opi- } \\
\text { oid consumption }\end{array}$ & Nil noted \\
\hline Vermeyloen & Analgesic duration & Prolonged 9h & - & & & Nil noted \\
\hline Cummings & $\begin{array}{l}\text { Analgesic duration } \\
\text { and postoperative } \\
\text { pain scores }\end{array}$ & $\begin{array}{l}\text { Prolonged } 1.9^{\star} \\
\text { with ropivacaine } \\
\text { and } 1.4^{\star} \text { with } \\
\text { bupivacaine }\end{array}$ & $\begin{array}{l}\text { Median maximum } \\
\text { verbal response } \\
\text { pain score signif- } \\
\text { icantly lower on } \\
\text { day } 1 \text { post-surgery }\end{array}$ & & $\begin{array}{c}\text { Reduced PONV } \\
\text { No significant re- } \\
\text { duction in opi- } \\
\text { oid use over } 72 \mathrm{~h} \\
\text { postop }\end{array}$ & $\begin{array}{l}\text { Nil observed } \\
\text { during 14-day } \\
\text { follow-up }\end{array}$ \\
\hline Movafegh & Analgesic duration & $\begin{array}{l}\text { Prolonged } 242 \pm 76 \\
\text { vs. } 98 \pm 33 \mathrm{~min}\end{array}$ & & & & Nil noted \\
\hline Parington & Analgesic duration & $\begin{array}{l}\text { Prolonged } 332 \text { vs. } \\
228 \mathrm{~min}\end{array}$ & & & $\begin{array}{l}\text { No difference in } \\
\text { analgesia onset } \\
\text { time }\end{array}$ & Nil noted \\
\hline Shrestha & Analgesic duration & $\begin{array}{l}\text { Prolonged } 1028 \\
\text { vs. } 453.17 \mathrm{~min}\end{array}$ & & & $\begin{array}{l}\text { Superior to tra- } \\
\text { maol as regional } \\
\text { adjuvant }\end{array}$ & Nil noted \\
\hline Shrestha & $\begin{array}{l}\text { Analgesic quality } \\
\text { and duration }\end{array}$ & $\begin{array}{l}\text { Prolonged } 834 \text { vs. } \\
\quad 274 \text { min }\end{array}$ & No difference & & $\begin{array}{l}\text { Faster onset of an- } \\
\text { algesia noted }\end{array}$ & Nil noted \\
\hline Tandoc & Analgesic duration & $\begin{array}{l}\text { Prolonged } 21.6 \\
(4 \mathrm{mg}) \text { and } \\
25.2(8 \mathrm{mg}) \text { vs. } \\
13.3 \mathrm{~h} \text { (control) }\end{array}$ & & & $\begin{array}{l}\text { Reduced addition- } \\
\text { al analgesic re- } \\
\text { quirements for } \\
48 \mathrm{~h} \text {. No significant } \\
\text { difference between } \\
\text { the two dexameth- } \\
\text { asone dosages with } \\
\text { regard to outcome }\end{array}$ & $\begin{array}{c}\text { Nil noted at } 4 \\
\text { weeks of follow-up }\end{array}$ \\
\hline
\end{tabular}


The use of dexamethasone as part of a multimodal pain management strategy has been the subject of much discussion in recent years. Almost all clinicians are behind the fact that it most likely affects the management of pain. Questions are asked about its intravenous application, whether epidural or perineural application is better, or what the dosage and duration of application should be. There are questions about the the exact mechanism of action, and the existence of adverse effects - early or late ones. Authors cite that, applied intravenously, dexamethasone again prolongs the effect of peripheral nerve blockade (20).

In 2016, Chun EH et al. conducted a study of two groups of patients who had an intercellular block for arthroscopic surgery on the shoulder joint. Dexamethasone $5 \mathrm{mg}$ is used on both groups - intravenously on one, and perineurally on the other. The results that they cite are definitely in favor of perineural application of dexamethasone, only there is a significant prolongation of the block with approximately $200 \mathrm{~min}$. Another study done with $4 \mathrm{mg}$ dexamethasone with one-way results (19) is similar in design.

Some authors share good results in knee replacement patients who received ketamine intravenous infusion $3 \mathrm{mcg} / \mathrm{kg} / \mathrm{min}$ intraoperatively and $1.5 \mathrm{mcg} / \mathrm{kg} / \mathrm{min} 48 \mathrm{~h}$ postoperatively. Ketamine influences the intensity of pain as well as prevents central pain sensitization. The use of ketamine reduces morphine consumption and shortens the time for patients to achieve 90 degrees of flexion on the knee joint. These authors suggest its application to regional femoral block (FB) techniques or epidural analge$\operatorname{sia}(21,15)$.

Several reports in the literature on topic adjuvants to local anesthetics commented on magnesium sulphate as a prolonged PNB agent and better results on the visual acuity scale (VAS) pain assessment and a total dose of added analgesics $(22,23)$. Magnesium demonstrates an antinociceptive effect in animal models and in humans. The antinociception effect is due to regulation of calcium influx. In the literature, there are various design studies where magnesium has been applied epidurally and the authors have registered a beneficial effect after its use with regard to opioid consumption and the extent of pain reported, i.e. co-administration of magnesium results in a better analgesic effect $(24,25)$.

A study from 2008 compares three control groups of patients with femoral perineural catheters infused with $0.2 \%$ ropivacaine $0.2 \%$, ropivacaine $0.2 \%+$ fentanyl $4 \mu \mathrm{g} / \mathrm{mL}$ and ropivacaine $0.2 \%+50$ $\mathrm{mg} / \mathrm{mL}$, respectively. The authors report a better and prolonged analgesic effect in the two adjuvants of fentanyl and magnesium, respectively, with the results in both groups being comparable (26).

Other authors deny the antinociceptive effect of fentanyl administered perineurally, indicating no significant difference in the outcome (27).

It is still unclear in the literature whether perineural application of an opioid (fentanyl) has a beneficial effect on PNBs. Clinicians share a potentiating analgesic potency of $100 \mathrm{mcg}$ of fentanyl added to a local anesthetic while performing an axillary block. They report a significant difference in the degree of analgesia, but also share a delayed onset of the block, as the most likely cause of this fact indicates a decrease in the $\mathrm{pH}$ of the fentanyl solution (28).

Until now, no theoretical rationale for the possible mechanism of action of perineural application of opioid has been found in the literature. In the axonal membrane of the afferent peripheral, nerve opioid receptors are absent. Following the physiological and pathophysiological mechanisms, the use of an opioid adjuvant to a local anesthetic for peripheral nerve blocking appears to be illogical (29).

It is very likely that the superficial analgesic effect reported, which in some patients is observed to be due to the systemic action of the opioid rather than the local one. To confirm a possible peripheral effect of opiates, sophisticated preclinical and clinical studies should be performed to justify the physiological and pathophysiological justification of possible beneficial results (27).

Studies comparing potential beneficial effects and possible neurotoxicity and other adverse effects do not support regular use in daily medical practice as adjuvants to local anesthetics, midazolam, magnesium, dexmedetomidine, and ketamine (30). Other authors set the question whether the addition of any adjuvant places the patient at an unnecessary risk without a certain benefit (30). 
Application of Dexamethasone as an Adjuvant to the Local Anesthetic in the Performance of a US-Guided Femoral Block ..

At the moment, in the official marketing authorizations of all the adjuvants discussed above, the perineural method of administration of the medication is not present (31).

\section{AIM}

The aim of this article is to investigate the effect of a dexamethasone adjuvant on the local anesthetic solution when performing a US-guided femoral block in patients after knee joint replacement.

\section{MATERIALS AND METHODS}

The scientific study was conducted at the Anesthesiology and Intensive Care Clinic and in the Orthopedic Clinic of the St. Marina University Hospital in the period from 2012 until 2017.

All patients treated in the Anesthesiology and Intensive Care Clinic were fasted by one of the following methods:

$\diamond$ Femoral block - long infusion through perineural catheter $+\mathrm{NE}$ opioid + SOS opioid.

$\diamond$ Single shot femoral block + NE opioid + SOS opioid.

Two groups were formed, one of which with two subgroups:

Group 1: single shot FNB + constant infusion through a perineural catheter $15 \mathrm{~mL}$ bolus (ropivacaine $0.5 \% /$ levobupivacaine $0.375 \%$ ) with a subsequent infusion of 5-9 mL per hour. The group consisted of 20 patients.

Group 2: single shot FNB $20 \mathrm{~mL}$ bolus (ropivacaine $0.5 \% /$ levobupivacaine $0.375 \%) \pm$ dexamethasone $4 \mathrm{mg}$. The group consisted of 33 patients. In this group, 2 subgroups were formed: patients with single shot FNB with chirocain - 10 patients; patients with single shot FNB with ropivacaine - 23 patients. Of

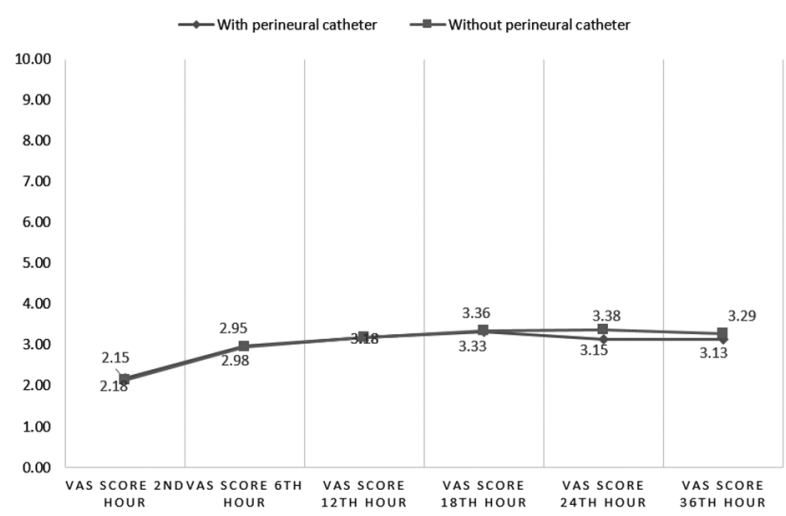

Fig. 1. VAS score in both subgroups with/without perineural femoral catheter

these, 15 patients were fasted with single shot FNB with ropivacaine + dexamethasone $4 \mathrm{mg}, 8$ patients with pure ropivacaine.

Evaluation of effective control of pain relief symptoms on $2^{\text {nd }}, 4^{\text {th }}, 6^{\text {th }}, 12^{\text {th }}, 18^{\text {th }}, 24^{\text {th }}$, and $36^{\text {th }}$ hours postoperatively was done according to VAS.

\section{RESULTS}

Comparison of the results in the VAS score in the two groups: Group 1 - single shot FNB + constant infusion through perineural catheter and Group 2 single shot $\mathrm{FNB} \pm$ dexamethasone.

No statistically significant difference in VAS values was observed with the use of a catheter in the $2^{\text {nd }}, 6^{\text {th }}, 12^{\text {th }}, 18^{\text {th }}$ and $36^{\text {th }}$ hours. Such was found only in the $24^{\text {th }}$ hour.

The curves practically overlap until the 18th hour, after which the patients with perineural catheter and a constant infusion of local anesthetic show a lower VAS score at the $24^{\text {th }}$ and $36^{\text {th }}$ hour.

Statistically significant is the difference only at the $24^{\text {th }}$ hour. Our results reported an advantage of the catheter technique after the 18th hour, the differ-

Table 2. VAS score in both subgroups with/without perineural catheter

Test Statistics ${ }^{\mathrm{a}}$

\begin{tabular}{lc|c|cccc} 
& $\begin{array}{c}\text { VAS score } \\
\mathbf{2}^{\text {nd }} \text { hour }\end{array}$ & $\begin{array}{c}\text { VAS score } \\
\mathbf{6}^{\text {th }} \text { hour }\end{array}$ & $\begin{array}{c}\text { VAS score } \\
\mathbf{1 2}^{\text {th }} \text { hour }\end{array}$ & $\begin{array}{c}\text { VAS score } \\
\mathbf{1 8}^{\text {th }} \text { hour }\end{array}$ & $\begin{array}{c}\text { VAS score } \\
\mathbf{2 4}^{\text {th }} \text { hour }\end{array}$ & $\begin{array}{c}\text { VAS score } \\
\mathbf{3 6}^{\text {th }} \text { hour }\end{array}$ \\
Mann-Whitney U & 319,500 & 320,500 & 315,000 & 292,500 & 214,000 & 252,500 \\
Wilcoxon W & 529,500 & 881,500 & 525,000 & 502,500 & 424,000 & 462,500 \\
Z &,- 296 &,- 344 &,- 334 &,- 787 & $-2,372$ & $-1,663$ \\
Asymp. Sig. (2-tailed) &, 767 &, 731 &, 738 &, 431 &, 018 &, 096 \\
\hline \hline
\end{tabular}

a. Grouping Variable: Perineural catheter 
ence being statistically significant at $24 \mathrm{~h}$. The same was the conclusion of Francis Salinas et al. in 2006.

It should be noted that the $24^{\text {th }}$ postoperative hour is the time for starting verticalization and rehabilitation of the patients in the Orthopedic Clinic at the St. Marina University Hospital, i.e. the muscular weakness of $m$. quadriceps femoris would be undesirable at this time.

Such a view of "single shot" preference technique is expressed in the Heeremans EH et al., 2012. Adding the higher price, time consumption, the requirements for higher qualification of the service staff (32), we think that for primary prosthesis the single shot FNB technique is more appropriate, with a view to early patient verticalization and rehabilitation, an early post-operative period outside of Anesthesiology and Intensive Care Clinic and a lower infection risk. Permanent catheter techniques are believed to be suitable for secondary and tertiary interventions that are more traumatic in which patients are in an Anesthesiology and Intensive Care Clinic and in which early verticalization and rehabilitation do not begin because of joint instability.

\section{Effect of Dexamethasone on VAS Score}

In 2015, based on the literature, we decided to start administering $4 \mathrm{mg}$ of dexamethasone to the local anesthetic solution at the time of the PNB. In this study, 15 patients in the single shot FNB group + ropivacaine had dexamethasone added as an adjuvant. Data processing reported a statistically significant difference after the $18^{\text {th }}$ hour, also in the $24^{\text {th }}$ and $36^{\text {th }}$, but they did not in benefit from dexamethasone (Fig. 2). The reported difference was a minimum $<0.5$ of the VAS score, which is within the error of the inquiry method and is of no clinical significance. We did not detect statistically significant benefits of this ad-

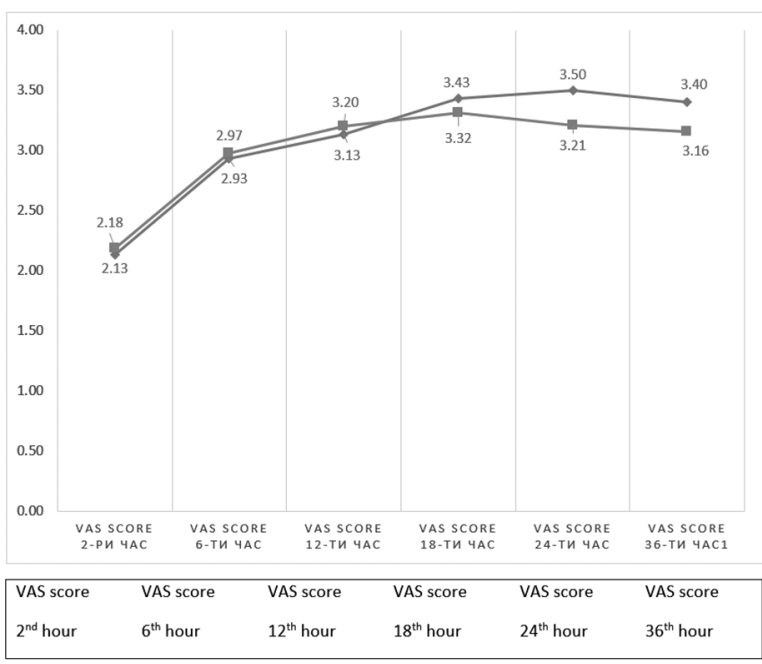

Fig. 2. Average VAS score in + (blue color)/- (red color) dexamethasone patients

${ }^{*}$ A large vertical chart magnification is applied because of the minimum difference in the parameter to better visualize

juvant. We did not have clinically registered ADRs. We have not established a correlation between these occurrences and the use of dexamethasone.

A statistically significant difference was observed in the $24^{\text {th }}$ and $36^{\text {th }}$ hours, and after the 18th hour.

\section{CONCLUSION}

Although our results correspond to those of authors who refute the positives of dexamethasone (12, 25) as an adjunct to PNB, we believe, based on clinical observation data, that it actually attenuated reversible hyperalgesia (patients did not report abrupt, acute, sudden onset of pain), therefore prolongation of the analgesic effect was observed until the $18^{\text {th }}, 20^{\text {th }}$ postoperative hour.

However, the number of patients and the validated scales we used did not show statistically significant adjuvant benefits at the indicated times.

Table 3. Median VAS score in patients anesthetized with PNB \pm dexamethasone

Test Statistics

\begin{tabular}{|c|c|c|c|c|c|c|}
\hline & $\begin{array}{l}\text { VAS score } \\
2^{\text {nd }} \text { hour }\end{array}$ & $\begin{array}{c}\text { VAS score } \\
6^{\text {th }} \text { hour }\end{array}$ & $\begin{array}{l}\text { VAS score } \\
12^{\text {th }} \text { hour }\end{array}$ & $\begin{array}{l}\text { VAS score } \\
18^{\text {th }} \text { hour }\end{array}$ & $\begin{array}{l}\text { VAS score } \\
24^{\text {th }} \text { hour }\end{array}$ & $\begin{array}{l}\text { VAS score } \\
36^{\text {th }} \text { hour }\end{array}$ \\
\hline Mann-Whitney U & 270,500 & 267,000 & 254,000 & 225,500 & 153,000 & 170,000 \\
\hline Wilcoxon W & 390,500 & 387,000 & 374,000 & 966,500 & 894,000 & 911,000 \\
\hline $\mathrm{Z}$ & -.440 & -.701 & -.743 & -1.343 & -2.905 & -2.656 \\
\hline Asymp. Sig. (2-tailed) & .660 & .483 & .458 & .179 & .004 & .008 \\
\hline
\end{tabular}

a. Grouping Variable: Dexamethasone to LA 
Application of Dexamethasone as an Adjuvant to the Local Anesthetic in the Performance of a US-Guided Femoral Block ..

\section{REFERENCES}

1. Yamashita A, Matsumoto M, Matsumoto S, Itoh M, Kawai K, Sakabe T. A comparison of the neurotoxic effects on the spinal cord of tetracaine, lidocaine, bupivacaine, and ropivacaine administered intrathecally in rabbits. Anesth Analg. 2003; 97(2):512-9.

2. Mather LE, Chang DH. Cardiotoxicity with modern local anaesthetics: is there a safer choice? Drugs. 2001; 61(3):333-42. doi: 10.2165/00003495-200161030-00002.

3. Pöpping DM, Elia N, Marret E, Wenk M, Tramèr MR. Clonidine as an adjuvant to local anesthetics for peripheral nerve and plexus blocks: a meta-analysis of randomized trials. Anesthesiology. 2009; 111(2):406-15. doi: 10.1097/ ALN.0b013e3181aae897.

4. Sharma B, Rupal S, Swami AC, Lata S. Effect of addition of dexmedetomidine to ropivacaine $0.2 \%$ for femoral nerve block in patients undergoing unilateral total knee replacement: A randomised doubleblind study. Indian J Anaesth. 2016; 60(6): 403-8. doi: 10.4103/0019-5049.183392.

5. Helal SM, Eskandr AM, Gaballah KM, Gaarour IS. Effects of perineural administration of dexmedetomidine in combination with bupivacaine in a femoral-sciatic nerve block. Saudi J Anaesth. 2016; 10(1):18-24. doi: 10.4103/1658-354X.169469.

6. Jakobsson J. Preoperative single-dose intravenous dexamethasone during ambulatory surgery: Update around the benefit versus risk. 2010;23(6):6826. doi: 10.1097/ACO.0b013e32833ff302.

7. Djalali AM. Is there a Role for IV Dexamethasone in Perioperative Pain Management? J Pain Relief. 2012;1:5. doi: 10.4172/2167-0846.1000e113.

8. Morales-Muñoz C, Sánchez-Ramos JL, DíazLara MD, González-González J, Gallego-Alonso I, Hernández-Del-Castillo MS. Analgesic effect of a single-dose of perineural dexamethasone on ultrasound-guided femoral nerve block after total knee replacement. Rev Esp Anestesiol Reanim. 2017; 64(1):19-26. doi: 10.1016/j.redar.2016.05.006.

9. Albrecht E, Kern C, and K R Kirkham. Perineural dexamethasone may significantly increase the duration of analgesia after regional blockade, though without dose-response effect. A systematic review and meta-analysis of perineural dexamethasone for peripheral nerve blocks. Anaesthesia. 2015; 70(1):71-83.
10. Webb BG, Sallay PI, McMurray SD, Misamore GW. Comparison of Interscalene Brachial Plexus Block Performed With and Without Steroids. Orthopedics. 2016; 39(6):e1100-3. doi: 10.3928/01477447-20160819-02.

11. Huynh TM, Marret E, Bonnet F. Combination of dexamethasone and local anaesthetic solution in peripheral nerve blocks: A meta-analysis of randomised controlled trials. Eur J Anaesthesiol. 2015; 32 (11): 751-8. doi: 10.1097/EJA.0000000000000248.

12. Sherif AA, Elsersy HE. Dexamethasone as adjuvant for femoral nerve block following knee arthroplasty: a randomized, controlled study. Acta Anaesthesiol Scand. 2016; 60(7):977-87. doi: 10.1111/ aas.12750.

13. Parra-Sanchez I, Parada C, Cummings III KC. Perioperative uses of dexamethasone. In: Sauvage A, Levy M (editors). Dexamethasone: Therapeutic uses, mechanism of action and potential side effects. Nova Publishers Inc. p. 137-58.

14. Bringmans D. Adjuvants for peripheral nerve blocks. Available at: http://www.uzleuven.be/sites/ default/files/Anesthesiologie/Presentatie\%20Bringmans.pdf

15. Azam Q, Sadat-Ali M, Badar A. Pain management in knee arthroplasty: an overview. Curr Orthop Prac. 2016; 27(4):360-70. doi: 10.1097/ BCO.0000000000000391.

16. An K, Elkassabany NM, Liu J. Dexamethasone as adjuvant to bupivacaine prolongs the duration of thermal antinociception and prevents bupivacaineinduced rebound hyperalgesia via regional mechanism in a mouse sciatic nerve block model. PLoS One. 2015; 10(4): e0123459. doi:10.1371/journal. pone. 0123459 .

17. Fredrickson Fanzca MJ, Danesh-Clough TK, White R. Adjuvant dexamethasone for bupivacaine sciatic and ankle blocks: results from 2 randomized placebo-controlled trials. Reg Anesth Pain Med. 2013; 38(4):300-7. doi: 10.1097/AAP.0b013e318292c121.

18. Pehora C, Pearson AM, Kaushal A, Crawford MW, Johnston B. Dexamethasone as an adjuvant to peripheral nerve block. Cochrane Database Syst Rev. 2017; 11:CD011770. doi: 10.1002/14651858. CD011770.pub2.

19. Kawanishi R, Yamamoto K, Tobetto $Y$, Nomura K, Kato M, Go R, et al. Perineural but not systemic low-dose dexamethasone prolongs the duration of interscalene block with ropivacaine: a prospec- 
Petya Ivanova, Nikolay Mladenov, Atanas Zanev et al.

tive randomized trial. Local Reg Anesth. 2014; 7:59. doi: 10.2147/LRA.S59158.

20. Desmet M, Braems H, Reynvoet M, Plasschaert S, Van Cauwelaert J, Pottel H, et al. I.V. and perineural dexamethasone are equivalent in increasing the analgesic duration of a single-shot interscalene block with ropivacaine for shoulder surgery: a prospective, randomized, placebo-controlled study. Br J Anaesth. 2013; 111(3):445-52. doi: 10.1093/bja/ aet109.

21. Adam F, Chauvin M, Manoir BD, Langlois M, Sessler DI, Fletcher D. Small dose ketamine improves postoperative analgesia and rehabilitation after total knee arthroplasty. Anesth Analg. 2005; 100(2):475-80. doi:10.1213/01. ANE.0000142117.82241.DC.

22. ELShamaa HA, Ibrahim M. Magnesium sulfate in femoral nerve block, does postoperative analgesia differ? A comparative study. Egypt J Anaesth. 2014;30(2):169-73.doi: 10.1016/j.egja.2013.10.005.

23. Muthiah T, Arora MK, Trikha A, Sunder RA, Prasad G, Singh PM. Efficacy of magnesium as an adjuvant to bupivacaine in 3-in-1 nerve block for arthroscopic anterior cruciate ligament repair. Indian J Anaesth. 2016; 60(7):491-5. doi: 10.4103/0019-5049.186018.

24. Daabiss MA, Kandil A. Evaluation of the effect of magnesium vs. midazolam as adjunct to epidural bupivacaine in patients undergoing total knee replacement. Br J Med Pract. 2013;6(2):a610.

25. Bilir A, Gulec S, Erkan A, Ozcelik A. Epidural magnesium reduces postoperative analgesic requirement. Br J Anaesth. 2007; 98(4):519-23. doi: 10.1093/bja/aem029.

26. Elmawgoud AA, Badaway A, Samaa Abd Elkassen, Doaa Rashwan. Effect of addition of magnesium sulphate and fentanyl to ropivacaine continuous femoral nerve block in patients undergoing elective total knee replacement. J Med Sci. 2008;8(4): 395-9. doi: 10.3923/jms.2008.395.399.

27. Heo BH1, Lee HJ, Lee HG, Kim MY, Park KS, Choi JI, et al. Femoral nerve block for patient undergoing total knee arthroplasty: Prospective, randomized, double-blinded study evaluating analgesic effect of perineural fentanyl additive to local anesthetics. Medicine (Baltimore). 2016; 95(36): e4771. doi: 10.1097/MD.0000000000004771.

28. Nishikawa K, Kanaya N, Nakayama M, Igarashi M, Tsunoda K, Namiki A. Fentanyl improves analgesia but prolongs the onset of axillary brachial plexus block by peripheral mechanism. Anesth Analg. 2000;91(2):384-7. doi: 10.1097/00000539-200008000-00028.

29. Weller RS, Butterworth J. Opioids as local anesthetic adjuvants for peripheral nerve block. Tech Reg Anesth Pain Manag. 2004; 8(3):123-8. doi:10.1053/j.trap.2004.03.005.

30. Bailard NS, Ortiz J, Flores RA. Additives to local anesthetics for peripheral nerve blocks: Evidence, limitations, and recommendations. Am J Health Syst Pharm. 2014; 71(5):373-85. doi: 10.2146/ ajhp130336.

31. Kirksey MA, Haskins SC, Cheng J, Liu SS. Local anesthetic peripheral nerve block adjuvants for prolongation of analgesia: A systematic qualitative review. PLoS ONE. 2015; 10(9):e0137312. doi:10.1371/ journal.pone.0137312.

32. Carvalho B, Yun RD, Mariano ER. Continuous versus single-injection peripheral nerve blocks: A prospective cohort study comparing procedural time and estimated personnel cost. Open Anesth J. 2015;9:1-5. 